\title{
Biliary Anastomotic Leakage
}

National Cancer Institute

\section{Source}

National Cancer Institute. Biliary Anastomotic Leakage. NCI Thesaurus. Code C78183.

Leakage of bile due to breakdown of a biliary anastomosis. 